$\xi=-1$

\title{
Experimental Study of Replacement the Tension Reinforcing Bars in Concrete Beams by Steel Pipes
}

\author{
Labeeb Saadoon Al-Yassri ${ }^{1 *}$, Alaa Mahdi Al-Khekany ${ }^{2}$, Hajer Satea Abbas ${ }^{3}$ \\ ${ }^{I}$ Factuality of Engineering, University of Al-Qadisiyah, Iraq: \\ ${ }^{2}$ Factuality of Engineering, University of Al-Qadisiyah, Iraq \\ ${ }^{3}$ Al-Esraa University, Baghdad, Iraq. \\ Authors Tel.: +964 7816764 606, +964 7810034028 \\ *Corresponding author E-mail: Labeeb.Husein@qu.edu.iq.
}

\begin{abstract}
Structures designed with reinforced concrete beams are used extensively in construction projects because of their functional and economic features. In this research, tested concrete beams were cast and reinforced with small diameter steel pipes and /or steel bars as flexural reinforcement to study the effect of this configuration of reinforcement on the structural behavior of reinforced concrete beams. The idea of this research involves performing and testing of four reinforced concrete beams reinforced by small diameter steel pipes with different percentages of replacement with traditional steel bars $(0 \%, 33 \%, 66 \%$ and $100 \%)$. The experimental results showed that using of steel pipes reduces the flexural capacity by $(2.7,18.3,37.5 \%)$ if compared with traditional steel bar according to the replacement percentages of $(33 \%, 66 \%$, and $100 \%)$ respectively. Moreover, the stiffness of beams reinforced with steel pipes (fully or partially) decreased as a result of the difference in the mechanical properties between steel bar and the steel pipe and also, the bond strength reduction between the smooth steel pipe and surrounded concrete.
\end{abstract}

Keywords: Reinforced concrete beam, steel pipes, steel bars, flexural strength, mode of failure

\section{Introduction}

In contemporary structural construction, transverse openings in strengthening concrete beams are regularly supplied for the passageway of utility pipes and ducts. These ducts are essential for the purpose of accommodating necessary facilities like electricity, water supply, telephone, and Internet. They are typically positioned under the beam soffit and for visual reasons, are enclosed by a suspended ceiling for generating a dead space. On every floor, this dead space height inserts the total building height in accordance with the amount and depth of ducts. For that reason, the web openings assist the civil engineer to decrease the structure height, particularly with respect to tall buildings, leading to an extremely cost-effective project [1-4]. All-inclusive reported papers concerning perforated and continuous RC beams with variable opening sizes, outlines, and positions for monotonic loading are explained in the literature as in [5-11].

\section{Opening Classification}

Here, we will detail about reinforced concrete beams with web openings using opening's size, outline and location. Openings can be categorized as small or big openings and the finest opening location is in accordance with its size. Web openings were found to take numerous forms like rectangular, circular, triangular, diamond, trapezoidal and uneven outlines.

On the other hand, rectangular and circular openings are the most conventional ones practically [12]. Depending on opening sizes, various scholars adopt the terms "small" and "large" with no any illustration about any clear-cut demarcation line. Small openings can be described as square, circular or almost square in outline [13]. Vice versa based on Somes and Corley [14], a circular opening is feasibly been as large if its diameter goes above 0.25 times the beam depth (h) and its length is less than or equivalent to its depth (d). Accordingly, the beam action can be presumed to prevail. Consequently, the investigation and project of a beam with small openings possibly take the comparable course of action as in solid beam. Small openings are, thus, defined as openings which are small enough and situated in such approach that a strut-tie model (STM) is capable of jumping over the openings without causing extra vertical or horizontal struts in the chords above and below the openings [15].

Large openings can be defined as an opening that requires additional vertical and horizontal struts in the chords above and below the opening. An opening is assumed large in the case of its depth (d) or diameter (D) is bigger than 0.25 times the depth of the beam (h) and its length $(\ell)$ is greater than its depth (d) for the reason that the outline of such openings decreases the strength of the beam and the beam type behavior will be, according to Somes and Corley [14]. According to the aforementioned analysis, it is obvious that openings possibly have numerous forms and the nonstop openings along the span of the beam have not been studied extensively yet. The authentic category and position of an opening should be obvious given before the project requirement phase.

\section{Research Significance}

A comparatively huge number of researches were examined the diverse foremost influences involved in the problem: cross- 
sectional properties, shear span-to-depth ratio, amount, category and position of web reinforcement, concrete strength, size, outline, and position of web opening.

Ashour and Rishi [16], were tested 16 continuous deep beams with rectangular openings to investigate the consequence of web reinforcement and the size and position of the opening. Particularly, openings within the inner shear span or in the exterior shear span have been taken into consideration. The failure mode was found chiefly reliant on the location of the opening and the uppermost load capacity decrease happened in the case of the placed opening in the interior shear span. Tan and Tang [17] were investigated the effect of inclined web reinforcement in deep beams with rectangular web openings, and a strut-and-tie model was proposed to estimate the strength of such beams. Yang and Eun [18], were tested thirty two deep beams with rectangular openings. The specimens had dissimilar concrete strength, and the opening size and the shear span-to-depth ratio varied from 0.5 to 1. The effect of concrete compressive strength on the loadcarrying capacity was found considerably reduced in deep beams with openings.

The openings existence in beams is regularly essential in buildings but utmost codes [19-21] do not make available an obvious design suggestions regarding this matter. Most investigational experiments in the literature [22] have examined RC beams with the transverse opening. No strong indication is presently given for the case of longitudinal openings. The transverse openings existence will convert uncomplicated beam into a more multifaceted behavior, as they make an impulsive alteration in the beam's cross-section dimension whereas the beam has longitudinal openings have a constant section along its span. Nevertheless, as the opening stands for a weakness source, the failure plane constantly goes throughout the opening. The definitive shear strength, crack width and stiffness are correspondingly being truly influenced. For this reason, this paper presents test of concrete beams reinforced with longitudinal steel pipe of so the crosssection of a beam will remain constant along the span. In this research, small diameter of steel pipes used to equivalent the small diameter of steel bars used in the referenced beam to study the effect of this replacement. At the same time, if we using of the large diameter of steel bars to reinforce a concrete beam (heavy reinforced beam), steel pipes of large diameter will be used to replace the heavy reinforcement. Therefore, the utility of using these pipes as ducts to pass all services through the beam so no need to cover by a suspended ceiling. In addition to that, the longitudinal opening of large size steel pipes will reduce the overall weight of the building, especially for a multistory building by eliminating of a suspended celling with a portion of the beam's weight.

\section{Experimental Program}

\subsection{Test Specimens}

Beam specimens with four types of reinforcement were manufactured. Figure (1) explains the geometric shape, dimensions, reinforcement parts and supporting conditions of the simply supported beam specimens used, the main geometrical dimensions of the beams were, overall depth equal to $250 \mathrm{~mm}$, width of section equal to $200 \mathrm{~mm}$, overall length equal to 1100 $\mathrm{mm}$ and with clear span equal to $1000 \mathrm{~mm}$. To prevent the shear failure, all beam varieties are designed so that the final failure is a flexural tensile failure. The size of deformed bar that used for stirrups and for top longitudinal steel reinforcement to fix it at all specimens was $\varphi 12 \mathrm{~mm}$, while the bottom longitudinal steel reinforcement was different from one to another to study the influence of steel pipe (see Figure 2). Details of specimens considered here were tabulated in Table (1). Various percentages of replacement of longitudinal steel rebar $\varnothing 12 \mathrm{~mm}$ by $\emptyset 20 \mathrm{~mm}$ steel pipes used in specimens were necessary to obtain the influence of continuous voids on the structural performance of this type of beam. Noteworthy, the diameter and thickness of steel pipes were chosen to equivalent the area of replaced bar.

Table 1: Specimen's descriptions

\begin{tabular}{|c|c|c|}
\hline Sample & Main Reinforcement & $\begin{array}{c}\text { Concrete Strength** } \\
(\mathrm{MPa})\end{array}$ \\
\hline $\mathrm{B} 0$ & $3 \varnothing 12 \mathrm{~mm}$ & 33.1 \\
\hline B1 & $\begin{array}{c}2 \varnothing 12 \mathrm{~mm}+1 \varnothing 20 \mathrm{~mm} \text { steel } \\
\text { pipe* }^{*}\end{array}$ & 30.6 \\
\hline B2 & $\begin{array}{c}1 \emptyset 12 \mathrm{~mm}+2 \varnothing 20 \mathrm{~mm} \text { steel } \\
\text { pipe * }\end{array}$ & 35 \\
\hline B3 & $3 \varnothing 20 \mathrm{~mm}$ steel pipe $*$ & 31.8 \\
\hline
\end{tabular}

* Steel pipe thickness $=1.75 \mathrm{~mm}$

**Cubic strength at the same time of the testing of specimen

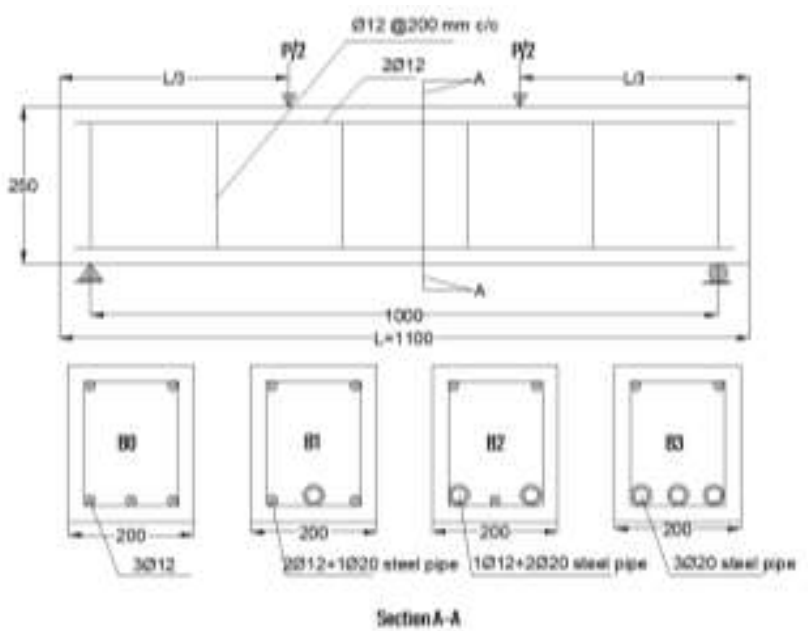

Fig.1: Details of the adopted specimens

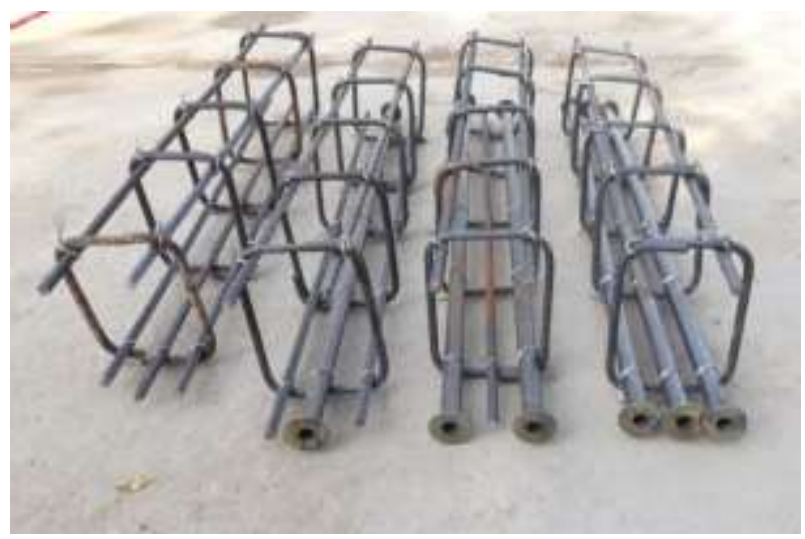

Fig. 2: Steel reinforcement of specimens

\subsection{Preparation of Beam Specimens}

All beam specimens have fabricated with the equivalent category of concrete (normal strength concrete). Concrete mixing has performed in a tilting pan type mixer as shown in Figure 3, with the subsequent proportions: cement: sand: aggregate $(1: 1.5: 3)$. The used cement was Portland cement (PC) and the cement was conforming to Iraqi Standard Specification No. 5-1984 [23]. The maximum size of natural sand used in this investigation was 4.8 $\mathrm{mm}$ while the maximum size of crushed gravel used in the current study was $19 \mathrm{~mm}$. The sand and the gravel were satisfied according to the aggregate grading and specification of Iraqi Specification No.45/1984 [24]. Tap water used for mixing of a concrete mixture. Mechanical properties of reinforcement used here are listed in Table 2. 
Table 2: Mechanical properties of reinforcement

\begin{tabular}{|c|c|c|c|c|}
\hline $\begin{array}{c}\text { Reinforcement } \\
\text { type }\end{array}$ & $\begin{array}{c}\text { Diameter } \\
(\mathrm{mm})\end{array}$ & $\begin{array}{c}\text { Yield } \\
\text { strength } \\
(\mathrm{MPa})\end{array}$ & $\begin{array}{c}\text { Ultimate } \\
\text { strength } \\
(\mathrm{MPa})\end{array}$ & $\begin{array}{c}\text { Elongation } \\
\%\end{array}$ \\
\hline $\begin{array}{c}\emptyset 12 \mathrm{~mm} \text { steel } \\
\text { bar }\end{array}$ & $11.93^{*}$ & $423^{*}$ & $637^{*}$ & $12.7 *$ \\
\hline $\begin{array}{c}\varnothing 20 \mathrm{~mm} \text { steel } \\
\text { pipe }\end{array}$ & $20^{* *}$ & $268^{* *}$ & $396^{* *}$ & --- \\
\hline
\end{tabular}

* Tests are conducted in the Constructional Materials Laboratory of College Engineering in Al-Qadisiyah University.

**Test are conducted by the manufacturer.

The beams were cast with the wood molds as the base. The molds were methodically cleaned earlier to concreting stage. After cleaning the molds, the internal surfaces oiled to prevent concrete adhesion with molds after concrete hardened. The casting was achieved in completely sustained settings on the laboratory floor as shown in Figure 3. Compaction was achieved by using electrical vibrating and a compaction rod to minimize the air voids and to get compacted concrete in a good way. After casting, the specimens were leveled by using a steel trowel. Finally, the samples were painting to recognize the cracks easily during testing the beams as shown in Figure 4. The beams were cast and cured for 28 days. The concrete features were evaluated from regular cubic specimens (as in normal strength concrete of $150 \mathrm{~mm}$ cube) Compressive strength was established by uncomplicated compression investigations and the typical magnitudes for all regular specimens were $33 \mathrm{MPa}$.

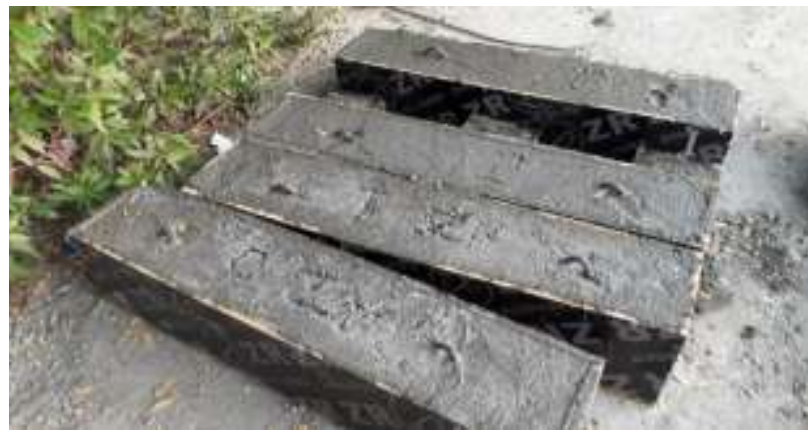

Fig. 3: Casting the Samples

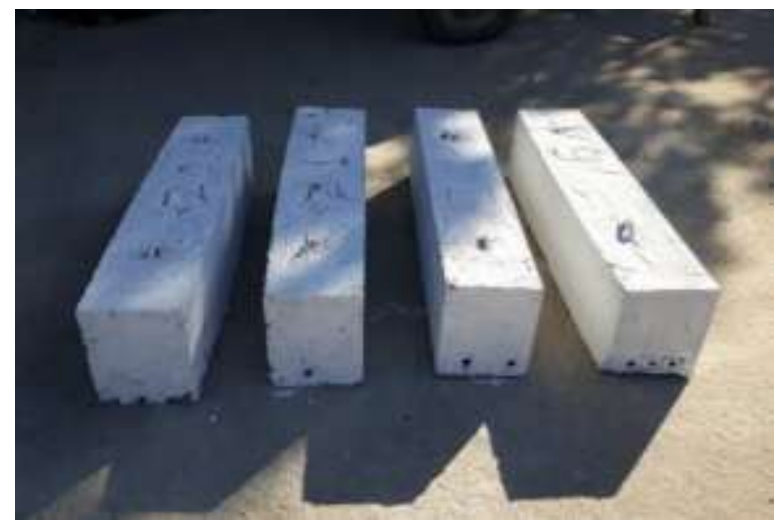

Fig. 4: Adopted samples

\subsection{Investigational Set-Up}

The objective of this research is to examine the structural performance of RC beams of a diverse number of voids along it's span creating by using steel pipes. The mid-span deflection is advantageous to evaluate the ductile or non-ductile performance of the beam. The midspan deflection of the beam has measured using dial gage transducers as shown in Figure 5. All beam specimens were simply supported with a clear span amid two supports equal to $1000 \mathrm{~mm}$.
A universal testing machine with a capacity of $1000 \mathrm{kN}$ has been employed to check all beam specimens under monotonic loads up to ultimate load. This universal machine is available at the Structural Laboratory of Civil Engineering Department in AlQadisiyah University as shown in Figure 5.

The load has been used as two points load distributed across the width of the beam by using steel plates placed across the width of the beam as shown in Figure 5. The load was applied incrementally by a mechanical controller.

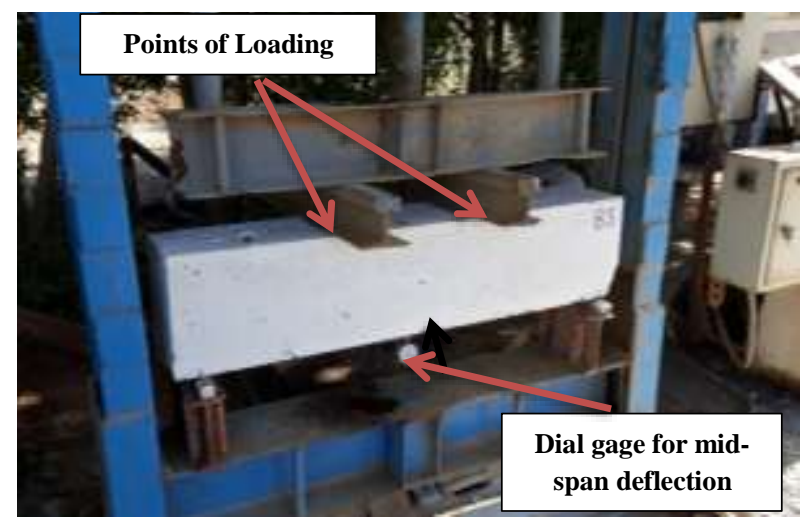

Fig. 5: Universal Test Machine and Loading Frame

\section{Results and Discussion}

The main aim of the on-hand research work is to examine the structural performance of reinforced concrete beams reinforced with steel pipes as mentioned above.

In general, there are three stages in load-deflection response, these stages are elastic-uncracked terminate when cracks develop, elastic-cracked until yielding developed and ultimate stage. In the cracking stage, vertical deflection increases linearly in all beam models with loading, this means that the materials in tension and compression zone are in an elastic state.

After this stage, there is a curvature in a load-deflection curve up to failure as in the slope of the load-deflection curve decreased largely with aggravated increments in deflection and a small increase in loading up to failure.

At an early stage of loading, all tested beams were free from cracks therefore, their behavior was in an elastic manner and deflection was proportional to the applied load. After then, flexural cracks were detected initially in the supreme moment region. As the load was augmented, the flexural cracks speared into a shear span. The depth of some of these cracks was regularly augmented and initiated to slope to the smeared loads.

Most of the beams failed in flexural tension, final failure occurred by the opening up of one of the diagonal cracks over the whole depth of the beam. Correspondingly, at this case, several horizontal cracks have been appeared on the tension reinforcement level. These horizontal cracks have been expanded to the beam end. This failure mode has specified a diagonal tension crack approach. A diagonal tension crack is described as a main inclined crack ranging from the longitudinal reinforcement level to the point load region Sethunarayanan, 1960 [25]. Some of these beams failed in flexural tension, final failure took place by widening of flexural cracks due to reaching the strain of tension reinforcement to the ultimate limit. Table 3 summarizes results of cracking, ultimate loads and corresponding deflection.

Table 3: Test results

\begin{tabular}{|c|c|c|c|c|c|}
\hline \multirow{2}{*}{$\begin{array}{c}\text { Beam } \\
\text { symbol }\end{array}$} & \multicolumn{2}{|c|}{ Cracking stage } & \multicolumn{2}{|c|}{ Ultimate stage } & \multirow{2}{*}{$\begin{array}{c}\text { Failure } \\
\text { mode }\end{array}$} \\
\hline & $\mathrm{P}(\mathrm{kN})$ & $\Delta(\mathrm{mm})$ & $\mathrm{P}(\mathrm{kN})$ & $\Delta(\mathrm{mm})$ & \\
\hline B0 & 42.9 & 0.78 & 171.6 & 5.5 & $\begin{array}{c}\text { Flexural } \\
\text { tensile }\end{array}$ \\
\hline B1 & 40.5 & 1.05 & 167 & 5.3 & Flexural \\
\hline
\end{tabular}




\begin{tabular}{|c|c|c|c|c|c|}
\hline & & & & & tensile \\
\hline B2 & 38 & 1.1 & 140.13 & 5.36 & $\begin{array}{c}\text { Bond } \\
\text { failure }\end{array}$ \\
\hline B3 & 35 & 1.07 & 107.25 & 7.2 & $\begin{array}{c}\text { Bond } \\
\text { failure }\end{array}$ \\
\hline
\end{tabular}

major crack opened more and flexural tensile failure followed by concrete crushing occur at a load of about $(167 \mathrm{kN})$ as shown in Figure (8). From Figure (9) the comparison with a reference (B0) specimen, it can be noticed, there is a decreasing in stiffness of this specimen due to the presence of a void, ultimate load

\subsection{Reference Beam $\left(B_{0}\right)$}

This reference beam specimen was made from normal strength concrete for overall its solid section and reinforced with $3 \varnothing 12 \mathrm{~mm}$ steel bars (see Figure 1), which regard as reference (control) specimen for comparison with other specimens. During the test of this control specimen, a first visible crack appeared in the constant moment region of the tension face of the beam (flexural crack) at load about $43 \mathrm{kN}$ ( as in $25 \%$ of ultimate load). As loading is increased, more cracks of flexure and diagonal shear began to appear on the tension face throughout beam at periods of loading, gradually increased in number, became wider and moved up along the width of the beam. At a load of $(128 \mathrm{kN})$ the cracks in the constant moment region at the tension face of beam began to widen. As the load was increased further, cracks continue to develop and widen also a loss in stiffness of the beam was occurring and one mode of failure appeared which can be classified as a flexural tension failure by yielding of tension reinforcing steel then concrete crushing in compression fiber at ultimate load $(171.6 \mathrm{kN})$ as shown in Figure 6. Figure 7, illustrate load-mid span deflection relationship

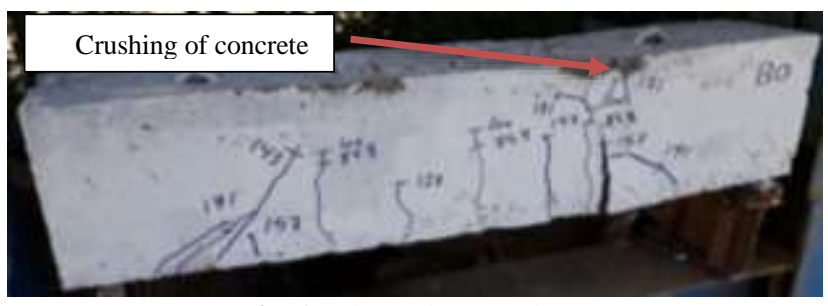

Fig. 6: Failure of B0 Specimen

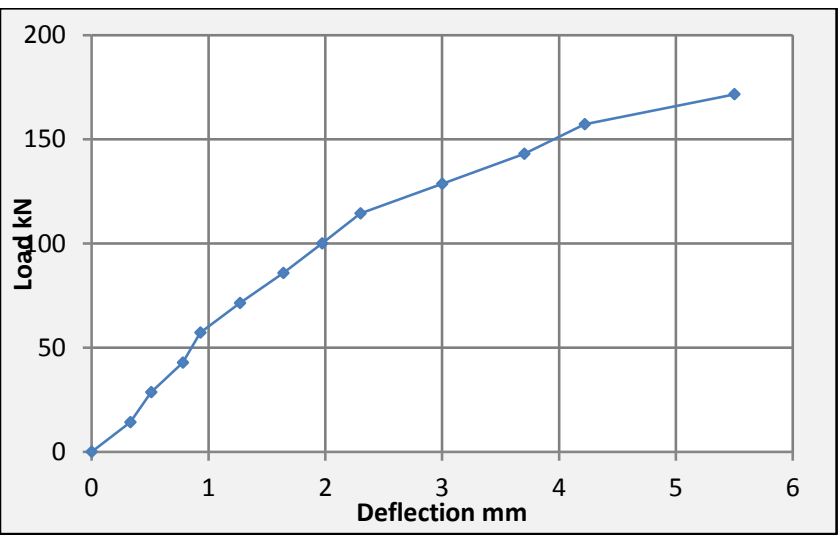

Fig. 7: Load-Mid Span Deflection Response of B0 Specimen

\subsection{Beam (B1)}

This beam specimen was made from normal strength concrete for overall its section and reinforced with 2- $\varnothing 12$ steel bar $+1-\varnothing 20 \mathrm{~mm}$ steel pipe (see Figure 1).

A first visible crack appeared within the constant moment region on the tension face of the beam (flexural crack) at load about 40.9 $\mathrm{kN}$ (as in $24.5 \%$ of ultimate load). More cracks of flexure and diagonal shear began to appear with increasing of a load on the tension face throughout the beam. It can be noticed the reduction in cracking load of about $4.9 \%$ relating to the specimen (B0). The intention of this reduction in stiffness of uncracked section is due to the fact that specimens with voided section have a lower uncracked moment of inertia (gross moment of inertia) that led to decreasing moment at which cracks occur. With increasing load, a decreased of about $2.7 \%$.

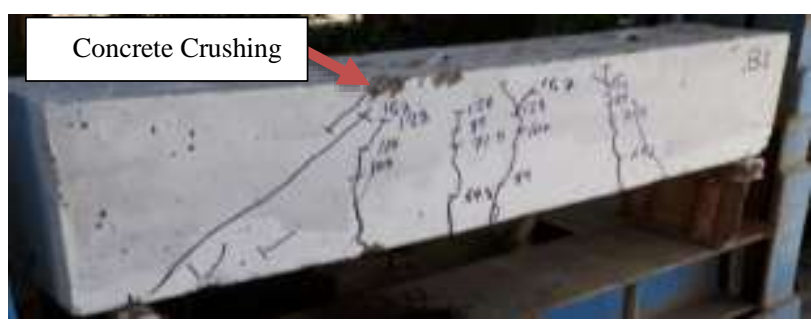

Fig. 8: Failure of B1 Specimen

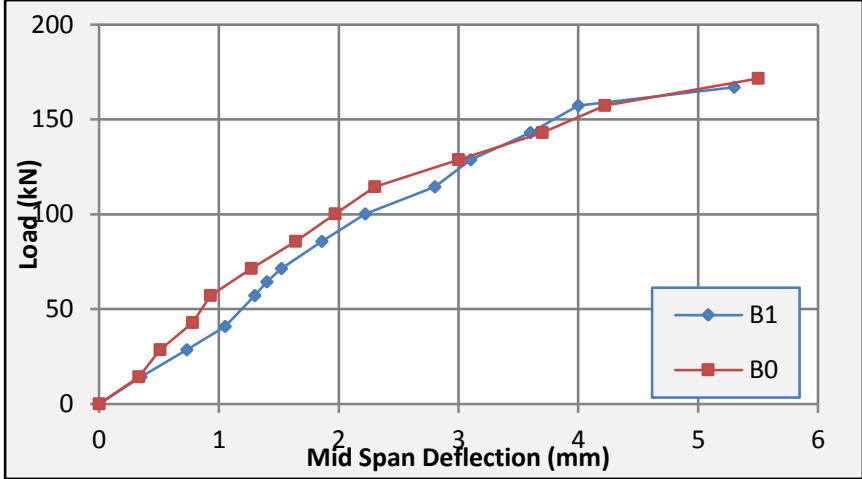

Fig. 9: Load-Mid span Deflection of B1 and B0 specimens

\subsection{Beam (B2)}

This beam specimen was fabricated from normal strength concrete reinforced with 1-ø12 steel bar $+2-\varnothing 20 \mathrm{~mm}$ steel pipes (see Figure 1). The first visible crack was formed on the tension face within the constant moment region at load about $38 \mathrm{kN}$ (27\% from ultimate load) With respect to the reference beam specimen (B0), cracking load decreased by about $11.6 \%$ due to the presence of steel pipes that led to a decrease in the gross moment of inertia. Later more cracks were generated in he constant moment region. For increased load, a major flexural crack opened more until sudden bond failure between tensile reinforcement and surrounding concrete occurred t a load of $(140 \mathrm{kN})$ as depicted in Figure (10). Figure (11) illustrates load-deflection responses of this specimen with (B0) specimen. It's clear that surface condition and stiffness of steel pipes led to the ultimate capacity of this specimen with respect to reference beam (B0).

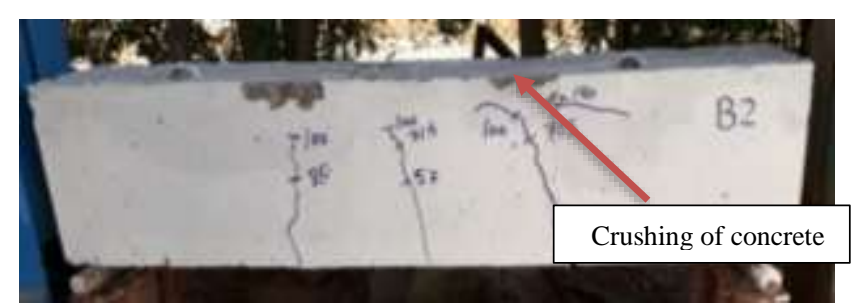

Fig. 10: Failure Mode of B2 Specimen 


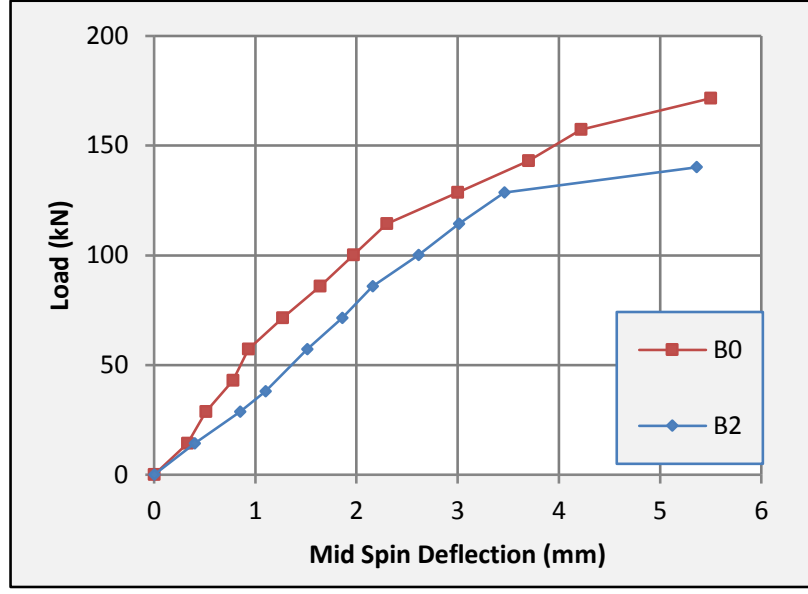

Fig. 11: Load-Mid span Deflection of B2 and B0 specimens

\subsection{Beam (B3)}

Same as other specimens this beam specimen was fabricated from normal strength concrete but reinforced with $3-\varnothing 20 \mathrm{~mm}$ steel pipes (see Figure 1). The first visible crack was formed at the tension face within the constant moment region at load about $35 \mathrm{kN}$ (32.7\% from ultimate load) With respect to the reference beam specimen (B0), cracking load decreased by about $18.6 \%$ due to the presence of steel pipes that led to a decrease in the gross moment of inertia. In the early stages of loading, slip between steel pipe and surrounding concrete were observed until the sudden bond slip failure occurred at $107.3 \mathrm{kN}$ as presented in the Figure (12). Figure (13) illustrates the load-mid span deflection of this beam with a reference beam (B0).

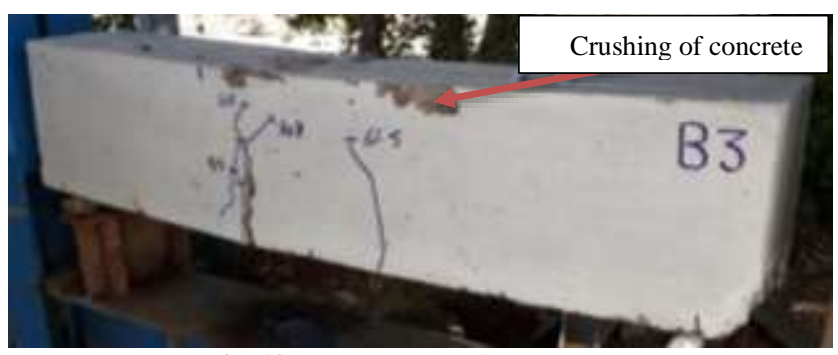

Fig. 12: Failure Mode of B3 specimen

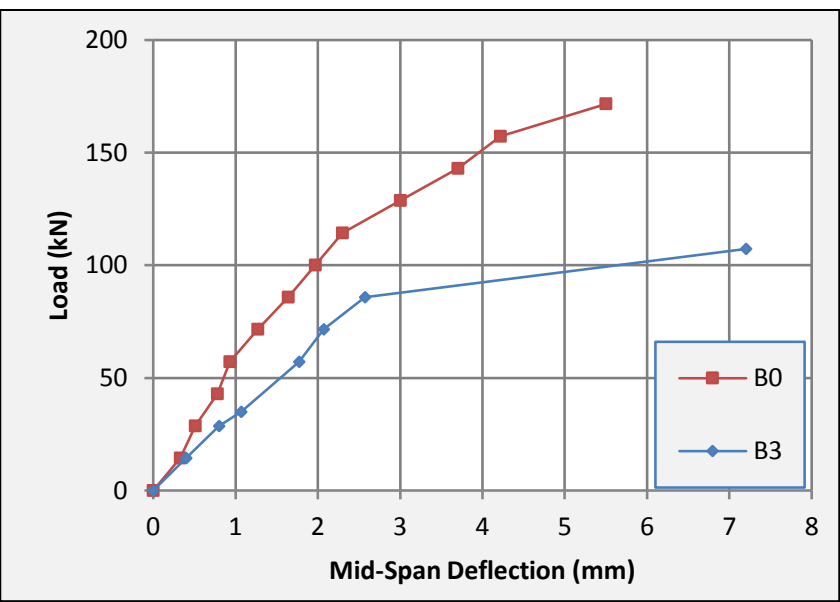

Fig. 13: Load-deflection Response of $B 3$ and $B 0$ Specimens

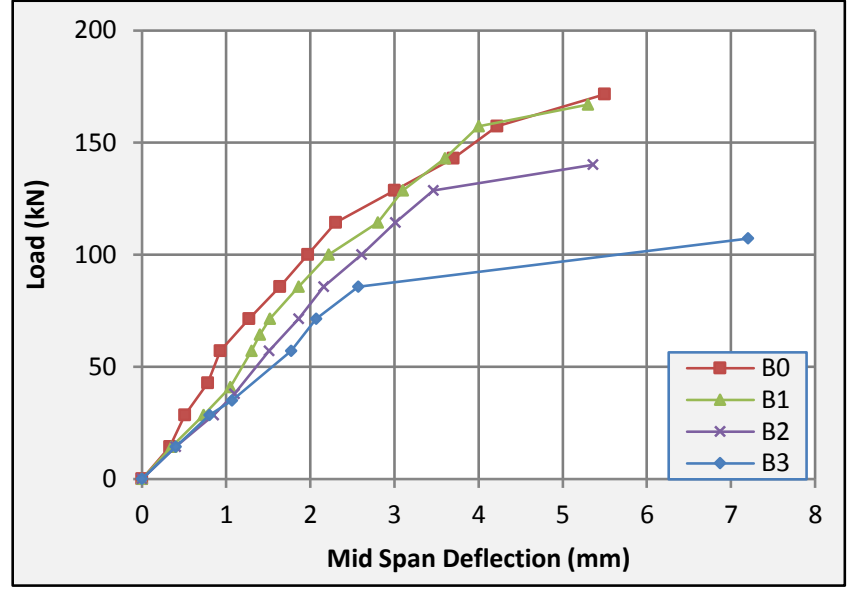

Fig. 14: Load Deflection Response of (B0, B1, B3, and B4) specimens

From Figure (14), it can be noticed that the stiffness of an uncracked section of beam decreased with increasing of the number of steel pipes used. This behavior can be attributed to decrease in the uncracked moment of inertia (gross moment of inertia of the section). Also, the decreasing of ultimate capacity can be attributed to the difference in elastic properties between rebars and steel pipes the led to a decrease of the internal lever arm. However, the premature bond failure prevented the (B2 and B3) specimens from reaching flexure capacity because the smooth surface of steel pipe led to decrease the bond stress and uniformity of cracks along the span of the specimen. This behavior can be obvious from cracking pattern

\section{Conclusion}

Based on the investigation studies that implemented in this research for the simply supported RC beam, the subsequent inferences can be drawn within the scope of this research:

1- Percentage of replacement $33 \%$ gives good results of ultimate strength, ductility and cracking pattern near to reference beam with the benefit from all advantages of longitudinal voids mentioned previously.

2- With an increasing percentage of replacement of rebar by steel pipes above $33 \%$, decreasing in bond stress will occur due to the smooth surface of its surface. Therefore, to increase bond stress between steel pipes and the surrounding concrete, the surface of these pipes must be roughened.

3- In addition to decreasing bond stress, the difference in elastic properties between rebars and steel pipes led to decreasing the ultimate strength capacity of beams reinforced with steel pipes fully or partially.

\section{References}

[1] A. Ahmed, M. Fayyadh, S. Naganathan and K. Nasharuddin (2012), Reinforced concrete beams with web openings: A state of the art review. Materials and Design 40, 90-102.

[2] Giuseppe C and Giovanni M (2012), Behaviour of concrete deep beams with openings and low shear span-to-depth ratio. Engineering Structures 41, 294-306.

[3] L. Herrera, S. Anacleto-Lupianez and A. Lemnitzer (2017), Experimental performance of RC moment frame beams with rectangular openings. Engineering Structures 152, 149-167.

[4] X.F. Nie, S.S. Zhang, J.G. Teng and G.M. Chen (2017), Experimental study on RC $\mathrm{T}$ section beams with an FRPstrengthened web Opening. Composite Structures 17, 4-8.

[5] Lorentsen M (1962), Holes in reinforced concrete girders. Byggmastaren 41 (7):141-52. J. Swedish Build. from Swedish by PCA, Chicago, Illinois.

[6] Nasser KW, Acavalos A and Daniel HR (1967), Behavior and design of large openings in reinforced concrete beams. ACI J Proc 64 (1), 25-33. 
[7] Prentzas EG. Behaviour and reinforcement of concrete beams with large rectangular apertures. United Kingdom: University of Sheffield; 1968

[8] Hanson JM. Square openings in webs of continuous joists. Portl. Cem. Assoc R D Lab Bull; 1969.

[9] Somes NF, Corley WG. Circular openings in webs of continuous beams. Spec Publ 1974; 42, 359-98.

[10] Salam SA. Beams with openings under different stress conditions. In: Proceeding of 3rd conference on our world in concrete and structures. Singapore: CI-Premier; 1977. p. 259-67.

[11] Mansur MA, Tan KH and Lee S-L. Collapse loads of R/C beams with large openings. J. Struct Eng 1984;110(11):2602-18.

[12] Prentzas EG. Behavior and reinforcement of concrete beams with large rectangular apertures. PhD Thesis, University of Sheffield, UK; 1968. p. 230.

[13] Hasnat A, Akhtaruzzaman AA (1987), Beams with small rectangular opening under torsion, bending and shear. ASCE J Struct Eng 113(10):2253-70.

[14] Somes NF and Corley WG (1974). Circular openings in webs of continuous beams. Shear in Reinforced Concrete, Special Publication SP-42. Detroit: American Concrete Institute;359-98.

[15] Waleed E, Salah E and Mohamed E (2015), Behavior of RC Shallow and Deep Beams with Openings Via the Strut-and- Tie Model Method and Nonlinear Finite Element. Arabian journal for science and engineering: DOI 10.1007/s13369-015-1678-x

[16] Ashour AF and Rishi G (2000), Test of reinforced concrete continuous deep beams with web openings. ACI Struct J 97(3), 418-26.

[17] Tan KH, Tang CY and Tong K (2004), Shear strength predictions of pierced deep beams with inclined web reinforcement. Mag Concr Res 56(8), 443-52.

[18] Yang KH, Eun HC and Chung HS (2006). The influence of web openings on the structural behavior of reinforced concrete highstrength concrete deep beams. Eng Struct 28:1825-34.

[19] ACI Committee 318. Building code requirements for structura concrete (ACI 318-08), and commentary (ACI 318R-08). American Concrete Institute, Detroit, Michigan; 2008. 430 pp.

[20] EN 1992-3:2006. Eurocode 2. Design of concrete structures; 2006.

[21] Canadian Standards Association (CSA), CAN/CSA-A23.3-04 (R2010), Design of concrete structures. Ontario: Rexdale; 2006.

[22] Yang KH, Eun HC and Chung HS (2006), The influence of web openings on the structural behavior of reinforced concrete highstrength concrete deep beams. Eng Struct 28, 1825-34.

[23] Iraqi Specification No.5, "Portland Cement", Baghdad, 1984.

[24] Iraqi Specification No.45, "Natural Sources for Gravel that is used in concrete and construction", Baghdad, 1984.

[25] Sethunarayanan, R., "Ultimate Strength of Pre-tensioned I-beams in combined Bending and Shear", Magazine of Concrete Research, Vol. (12), No. (35), July 1960, pp. 83-90 